\title{
Letter to the Editor regarding "Chiari I malformation and pregnancy: a comprehensive review of the literature to address common questions and to guide management."
}

\author{
Joanna C. Roper ${ }^{1}$ (D) Bassel H. Al Wattar ${ }^{2,3}$ \\ Received: 12 October 2020 / Accepted: 16 December 2020 / Published online: 3 January 2021 \\ (C) The Author(s), under exclusive licence to Springer-Verlag GmbH, AT part of Springer Nature 2021
}

Dear Editor:

We read with interest this comprehensive review by Sastry et al. [1] on the optimal management of pregnant women with Chiari I malformation. Given the uncertainty on the optimal management and the high stakes of adverse maternal outcomes, we agree with the authors on the need for a multidisciplinary careful evaluation of maternal symptoms early-on in pregnancy to plan intrapartum care accordingly and mitigate ensuing risks.

We recently published our local experience as a tertiary referral centre in the UK presenting data on 21 women with 23 pregnancies over a 14-year period [2]. While, sadly, our data was not included in this review, we largely concur with the author about the relative safety of vaginal delivery with neuraxial anaesthesia. Our data included $65.2 \%$ normal vaginal deliveries and $26.1 \%$ elective caesarean sections, with no neurological sequalae recorded. We hope our contribution would help the readers and practicing physicians to gain a wider perspective on this issue and offer safe care to women with Chiari I malformation.

Yours faithfully, Dr. Joanna C. Roper and Dr. Bassel H. Al Wattar

\section{References}

1. Sastry R, Sufianov R, Laviv Y, Young BC, Rojas R, Bhadelia R, Boone MD, Kasper EM (2020) Chiari I malformation and pregnancy: a comprehensive review of the literature to address common questions and to guide management. Acta Neurochir 162(7):15651573

2. Roper JC, Al Wattar BH, Silva AHD, Samarasekera S, Flint G, Pirie AM (2018) Management and birth outcomes of pregnant women with Chiari malformations: a 14 years retrospective case series. Eur J Obstet Gynecol Reprod Biol 230:1-5

Publisher's note Springer Nature remains neutral with regard to jurisdictional claims in published maps and institutional affiliations.
This article is part of the Topical Collection on Neurosurgery and pregnancy

Joanna C. Roper

Joanna.roper1@nhs.net

1 Obstetrics and Gynaecology, Croydon University Hospital, 530

London Rd, Thornton Heath CR7 7YE, UK

2 Warwick Medical School, University of Warwick, Coventry, UK

3 Reproductive Medicine Unit, University College London Hospitals, London, UK 